\title{
TOWARDS A JOINT FRAMEWORK FOR THE STUDY OF CHRISTIANS AND MUSLIMS IN AFRICA: RESPONSE TO J. D. Y. PEEL
}

\author{
Birgit Meyer
}

The main point of John Peel's intriguing critical intervention is to warn against what he sees as an overemphasis on similarities between Christianity and Islam. Making these religions look all too similar, he argues, may come at the expense of paying due attention to the distinctiveness of each of these religious traditions and hence to their intrinsic differences. He suggests an analogy between the stance taken by 'somewhat left-wing and anti-establishment discourse' to equalize Islam and Christianity under the label of fundamentalism on the one hand, and a strand of Africanist work on West Africa that pleads for the close similarities between these two religions to be acknowledged on the other. For the latter, he takes the article 'Pentecostalism, Islam and culture: new religious movements in West Africa' by Brian Larkin and myself (2006) as paradigmatic. For my part, it is difficult to see how the use of the notion of fundamentalism in current debates and the position ventured by us converge. I would certainly refrain from using the notion of fundamentalism (even if invoked to balance Huntington's equally problematic notion of the clash of civilizations) as a category that serves to draw out similarities between certain radical movements in Christianity and Islam both past and present - a use I view as highly problematic. The fact that Peel converges the levels of general public debate about political Islam and research regarding Christianity and Islam in African studies makes it quite difficult for me to grasp what his main concern is. Is it a worry about a - in his view - problematic, broader trend of denying actual intrinsic differences between Christianity and Islam, a trend that spills over from critical opinion into current Africanist scholarship, or vice versa? Is it the problem that foregrounding certain formal - and to him ultimately superficial - similarities favours an ahistorical stance with regard to these traditions? Or is it a concern - albeit not explicitly articulated - that the insistence on similarities with regard to Christianity might draw a too positive picture of Islam, pre-empting it from the critique that he considers necessary?

These are large and complicated questions. I cannot tackle here the difficult relationship between issues addressed by scholars in the study of religion and by public debates about the rise and presence of radical religious movements, especially in the sphere of Islam. Suffice it to note that Larkin's and my critique of the division of the study of religion in Africa into two separate and mutually exclusive fields of expertise, focusing on Christianity and Islam - a division that has been dominant until now - led us to argue for the recognition of unexpected similarities between Islamic and Christian reform movements in West Africa. We argued that the strong emphasis placed on differences between these religious

BIRGIT MEYER is Professor of Religious Studies at Utrecht University. Email: b.meyer@uu.nl

(C) International African Institute 2016

Downloaded from https://www.cambridge.org/core. Universiteitsbibliotheek Utrecht, on 18 Feb 2019 at 22:35:07, subject to the Cambridge Core 
traditions on the part of their respective followers, as well as in public debates in Nigeria and Ghana, should not be taken at face value by scholars. We intended our intervention to trigger a restructuring of scholarly inquiry in order to move beyond the current, poorly considered compartmentalization of the study of religion in Africa into separate fields devoted to Christianity and Islam, fields that are barely in conversation with each other. Certain new initiatives notwithstanding (see, for example, Janson and Soares, this issue), ${ }^{1}$ ten years later this situation has not yet changed substantially. Rather, with the rise of distinct anthropologies of Islam and Christianity, which have introduced a strong emphasis on their respective theologies, the cleavage has been widened. In my view, the need to look at both traditions together in the past and the present is more pertinent than ever. It is high time to pursue this intellectual project, and for this reason I am grateful to J. D. Y. Peel for engaging with our article. However, I feel that he overrates the thrust of our argument. Of course, our piece does not offer a fully fledged paradigm for the study of Christianity and Islam on the basis of similarity; it was intended as a provocative intervention. Engaging with some of the points raised by Peel, I offer this response as a constructive contribution to further develop the study of Christianity and Islam, Christians and Muslims, within one conceptual framework.

\section{SIMILARITY AND DIFFERENCE}

I agree with Peel that the way in which we designed our case (with Larkin's expertise on Islam in Northern Nigeria and mine on Christianity in Southern Ghana) is far from 'logically ideal'. It would certainly have been better to compare Pentecostal and Islamic reform movements within one nation state - either Ghana or Nigeria - and then engage in a subsequent comparison of the similarities and differences between these movements on the level of both states. I also concede that our suggestion to view these movements as 'mirror images' or 'doppelgängers' of each other overstates the case. With hindsight, I think that these terms - intended as a provocation - lend themselves to being misunderstood, making it seem as if we are arguing that these new movements converge to such an extent that differences between Islam and Christianity disappear entirely. For me, this was not the case then, and certainly is not the case now. Our point was that both show unexpected, partial similarities. So I think that basically Peel and I agree that the comparative study of Islam and Christianity should draw out differences and similarities, even though in our respective pieces we place a different emphasis on either the former or the latter, partly for strategic reasons.

The larger issue here is about comparison. The identification of differences necessarily requires a common ground. In other words, comparison depends on some kind of mediating category that asserts a degree of similarity on the basis

\footnotetext{
${ }^{1}$ See also Insa Nolte's fascinating European Research Council (ERC) research project 'Knowing each other: everyday religious encounters, social identities and tolerance in southwest Nigeria', which explores Christian-Muslim relations among the Yoruba on the level of the everyday: <http://www.birmingham.ac.uk/schools/historycultures/departments/dasa/research/ knowing/project.aspx>.
} 
of which differences become apparent. The study of Islam and Christianity in one conceptual framework raises the question of which mediating categories to choose in order to assess similarities and differences. In Peel's intervention, the mediating category that forms the basis on which Islam and Christianity are claimed to be substantially different is the broad notion of 'world religion'. This problematic category has rightly been criticized for serving to essentialize and de-contextualize so-called world religions, thereby claiming a false, de-historicized equivalence. In the light of Peel's strong plea against a presentist perspective - one that emphasizes context at the expense of history - I find it quite ironic that, in insisting on the differences between Islam and Christianity by referring to the category of world religion, he tends towards an essentializing take on these two religious traditions. I will pursue this point below.

So, how can we develop a comparative perspective without relying - albeit implicitly - on the category of world religion? When we wrote our article, we did not spell out the conceptual implications of studying Christianity and Islam within one framework; in fact, at that time, I had only just started thinking about this question. Now I see much more clearly that my aim is not a comparison of Islam and Christianity per se, but their comparison in relation to certain issues faced by both Christian and Muslim movements: for instance, the use of (mass) media, spatial practices and buildings, stances to indigenous culture, and so on. In short, the point is to identify mediating categories within the contexts - both past and present - in which Muslims and Christians coexist. Consciously locating a comparison on the level of a shared setting is productive because it allows for a situated assessment of similarities and differences, and allows attention to be paid to their interrelations. This is what we sought to do in our article, and I still see this as a productive starting point for the study of religiously plural settings as we encounter them - in different shapes and with different majority-minority relations in West Africa. Moreover, placing Christian and Islamic traditions within one setting and comparing them in relation to specific third categories brings to the fore actual encounters and entanglements. ${ }^{2}$

\section{CONTEXT AND TRADITION}

Peel is right in that our article is oriented towards the present. Reading his piece (and thinking about his overall work), I very much realize the importance of a historical approach. Still, I do not agree with his suggestion that a strong emphasis on context - as argued for in our article - necessarily comes at the expense of assessing the specificity of each religious tradition and its past trajectories. Nor do I agree with him that the spotting of similarities is a presentist endeavour, while a focus on differences would keep the past in the picture. This bundling of

\footnotetext{
${ }^{2}$ This is the starting point of the research programme 'Habitats and habitus: politics and aesthetics of religious world-making', which I am conducting at the Zentrum Moderner Orient in Berlin and which focuses on Muslims and Christians in Nigeria (Abuja) and Zanzibar (see Meyer 2014). See also the evocative exhibition curated by Marloes Janson with photographs by Akintunde Akinleye, 'The spiritual highway: religious world making in mega-city Lagos' (Janson 2014): <https://www.soas.ac.uk/gallery/spiritual-highway/>.
} 
antinomies - present versus past, similarity versus difference, and context versus tradition - is unfortunate. Invoking context and tradition as an opposition is problematic because this pre-empts questions about the past contexts in which these religious traditions were shaped.

The use of this set of conceptual antinomies does not, in fact, do justice to his own call to place Christianity and Islam in a historical perspective, a call I very much endorse. It is indeed of utmost importance to acknowledge the different conditions under which Islam and Christianity spread in West Africa, taking into account Usman dan Fodio's jihad, which led to the establishment of the Sokoto Caliphate, in which no formal distinction was made between religion and politics, on the one hand, and, on the other, the rise of Christianity through the activities of Western missions that were already predicated on a modern, colonial differentiation of religion and politics as separate spheres. Certainly, current new Pentecostal and Islamic movements need to be positioned in relation to these developments (Peel does so explicitly with regard to movements in the Islamic spectrum, but not for Pentecostalism). While in his contribution Peel asserts that Islam and Christianity are different, I would rather seek to explain their differences by taking into account the specific conditions of their spread.

More comparative research needs to be conducted on the past trajectories of Christianity and Islam, and on the complex relations between Muslims and Christians that ensued. In order to proceed in this direction, the invocation of one Christian and one Islamic tradition - upgraded to the level of world religions - is problematic. The fact that the spheres of Christianity and Islam contain a diverse set of movements - and that intriguing phenomena emerge in between, such as Chrislam and NASFAT ${ }^{3}$ - should serve as a warning against talking about two distinct traditions with their intrinsic features in the singular. Moreover, the examples given by Peel himself show that, in Nigeria, Christianity and Islam have been deployed in specific, historically situated environments in the light of which the distinction between context and tradition appears quite artificial. More interesting, at least in my view, is to study in detail how religious traditions in the spheres of Christianity and Islam - and in between - are reformed and transformed in specific contexts, looking closely at the ways in which economic, social, political and technological developments are negotiated. Recently, the adoption of mass media by Muslims and Christians has been a case in point for a detailed assessment of how religious reform occurs. But, of course, such processes are not limited to the (recent) present, but occur across time. Hence, while Peel is absolutely right in warning against presentism, I refute his claim that a focus on context implies the sin of presentism and, in addition, overrates similarity at the expense of specificity.

\section{FORM AND CONTENT}

The third, and last, issue I would like to raise - briefly - concerns the relation between form and content. Peel argues that our argument about the similarity

\footnotetext{
${ }^{3}$ NASFAT is the Nasrul-Lahi-il Fathi Society of Nigeria.
} 
of Christian and Islamic movements rests on emphasis being placed on mere formal characteristics at the expense of content. In this way, superficiality gains over substance. While we did not use the dualism of content and form - which is reminiscent of a typically Protestant distinction between inward substance and mere outward shape - I am certainly prepared to argue in favour of acknowledging the importance of form. Form, as I argued in work that appeared after our 2006 article (for example, Meyer 2010), is unduly underrated in the study of religion. This goes together with a longstanding inclination on the part of researchers to look through actual expressions of religion, aiming to go straight to a more or less hidden substance behind. In my view, form shapes content, and so they cannot be separated in this manner. In his comment in this section, Larkin addresses in some detail the importance of taking form seriously. Therefore, it is sufficient here to stress that attention to the ways and styles of 'doing religion' and 'being religious' is central to the development of a conceptual framework for the joint study of Christianity and Islam. In fact, an overriding concern with content may be one of the factors that hamper such a joint study. Taking form seriously does not imply missing out on the 'real thing'; rather, it allows convergences and commonalities to be spotted in the ways in which Islamic and Christian traditions take place in the world. In this sense, a focus on form is the sine qua non for the deployment of a joint framework for the study of Islam and Christianity in Africa in the past and present.

\section{REFERENCES}

Janson, M. (2014) The Spiritual Highway: religious world making in mega-city Lagos. With photographs by A. Akinleye. London: Brunei Gallery, SOAS.

Larkin, B. and B. Meyer (2006) 'Pentecostalism, Islam and culture: new religious movements in West Africa' in E. K. Akyeampong (ed.), Themes in West Africa's History. Oxford: James Currey.

Meyer, B. (2010) 'Aesthetics of persuasion: global Christianity and Pentecostalism's sensational forms', South Atlantic Quarterly, special issue on 'Global Christianity, global critique', 9: 741-63.

Meyer, B. (2014) 'Comment on "Researching Muslim worlds: regions and disciplines" by Ulrike Freitag'. Berlin: Zentrum Moderner Orient <http://www. zmo.de/publikationen/Kommentare/meyer_pp6.pdf>. 